\title{
HAVE AS A FUNCTION WORD
}

\author{
Chardes C. Fries \\ English Language Institute \\ University of Michigan
}

$\mathbf{T}$

HE ENGLISH WORD have not only expresses the full word meaning "to possess," "to own," "to experience," etc.; it also appears in a variety of structures with other verbs, as the signal of certain meanings sometimes classed as "aspect." Of these meanings the one most usually described in the grammars is "completed action" indicated by have (has, had) together with a "past participle" form. There are, however, at least two others that need special attention for practical teaching. The following statement seeks to furnish, not a complete description of all the details of these uses, but a helpful outline of only the chief contrasts.

I. Each of the three "function word" meanings attaches to the word have in a particular construction which can be indicated in a brief formula.

II. The word have can appear in the same structure both as a function word and as a full word verb.

III. The word have can appear in several positions of various combinations of the structures shown in the formulas with a double structural use for a single have.

I

\section{Three formulas of constructions with have as a} function word

(1) have + to + "infinitive" (or simple form of verb)

expresses "necessity" or "obligation."

Examples are

The men have to work hard.

They have to be there before ten.

They have to go to the city.

Each pilgrim had to tell a story.

This meaning of "necessity" or "obligation" regularly attaches to have and to with this verb form only in the arrangement given in 
the formula. If the order is shifted from "They have to tell a story" to "They have a story to tell" the meaning of have is usually that of one of the meanings of the full word, "to possess," etc.

(2) (a) have $+\mathrm{N}^{1}+$ "infinitive" (or simple form of verb) expresses a "directive," a "causative."

Examples are

They have their boy do the actual work.

They had a servant bring the books.

The manager had his clerks count the tickets.

This meaning of a "causative" or "directive" regularly attaches to have in this construction only with the "unmarked" infinitive without the word to. With the word $t o$ before the infinitive the word have, as shown above, usually has some one of the full word meanings, "to possess," "to own," etc. Contrast, for example, the following pairs of sentences.

The manager had his clerks count the tickets.

The manager had his clerks to count the tickets.

They have their boy do the actual work.

They have their boy to do the actual work.

They had a servant bring the books.

They had a servant to bring the books.

(b) This meaning of a "causative" or "directive" does, however, also usually attach to have when the verb form following is a "past participle."

$$
\begin{aligned}
& \text { have + } \mathrm{N}+\text { "past participle" } \\
& \text { expresses a "directive" or "causative." }
\end{aligned}
$$

With the unmarked infinitive as in (a) the $\mathrm{N}$ is the performer of the act; with the past participle as in (b) the $N$ is the goal or the receiver of the act.

Examples are

They have a story told each evening.

The manager had the tickets counted by his clerks. ${ }^{2}$

${ }^{1}$ In these formulas $\mathrm{N}$ represents any substantive, frequently a noun.

2 To avoid complication I have not included examples of the much less frequent but older arrangement that indicates a completed action. Unless special other structural clues are present expressions with this arrangement are frequently ambiguous. In the example "The manager had the tickets counted when we arrived," the had $+\mathrm{N}+\mathrm{pp}$. may be formula 2 (b) indicating that 
They had the books brought by a servant.

They have the actual work done by their boy.

(3) have + "past participle"

Examples are

$$
\text { expresses "completed action." }
$$

The clerks have counted the slips.

Their boy had done the actual work.

They have told a story each evening.

This use of have is also limited to the particular arrangement shown in the formula. Contrast, for example, the following pairs of sentences:

They have told a story to the younger boys each evening.

They have a story told to the younger boys each evening.

The instructor had scored the tests by machine.

The instructor had the tests scored by machine.

The following sentences bring together'the contrasts described above:

The instructor had to score his tests by a machine.

(have + to + infinitive expresses "necessity")

The instructor had a machine score his tests.

(have $+\mathrm{N}+$ infinitive expresses a "causative" with $\mathrm{N}$ as "performer")

The instructor had a machine to score his tests.

(have $+\mathrm{N}+$ to + infinitive, is not a function word use of have but has some of its full word meanings such as "possession," "ownership," etc.)

the manager "caused" the tickets to be counted when we arrived, or the had may indicate that he had completed the operation by that time. The latter is an arrangement and use that historically precedes the much more common arrangement "The manager had counted the tickets when we arrived."

Other examples of this older arrangment which are less ambiguous are

She had her hand caught in the machine.

He had his leg broken by a fall from the roof.

I have also not included any comment on a variation of meaning which results from a shift of intonation pattern and the introduction of pauses in such examples as "The manager had the tickets, counted by his clerks." It would have been more accurate and perhaps better protected against misinterpretation had I given all the examples in phonemic notation with the significant features of intonation and pause marked, but for a variety of reasons I felt that this outline might be more helpful in centering attention upon the chief contrasts with the examples as given here in conventional spelling. 
The instructor had his tests scored by a machine.

(have $+\mathrm{N}+\mathrm{pp}$. expresses a "causative" with $\mathrm{N}$ as "goal" or "object.")

The instructor had scored his tests by a machine. (have + pp. expresses "completed action.")

II

Have in the same structure both as a function word and as a full word verb

(1) have + to + inf. (necessity)

They have to have pencils.

The children all have to have a story to tell.

The men have to have work to do.

We have to have sufficient money for the trip.

The doorman has to have another uniform.

(2) have $+\mathrm{N}+$ inf. (causative)

The teachers have the students have their notebooks in their pockets.

They had their clerks have all the reward.

(3) have + pp. (completed action)

They have had their reward.

The instructor has had his degree for several years.

The boys had had their meeting early.

\section{III}

Have in several positions of various combinations of the structures shown in the formulas with a double structural use for a single have

They have to have the students pay their own fares.

They have had to have the students pay their own fares.

They have had to have the students have their parents send the money.

They have had to have the students have the money sent by their parents.

In each of these instances of combinations of the three types of structure, there is at least one example of the word have with a double use. First, it operates as a function word with reference to the form following, and, second, it fulfills the part required of a full word verb in one of the formulas given above. For instance, in the 
example "They have to have the students pay their own fares" the have following the word to operates as a full word verb would in relation to the first have to make the structure have + to + inf. But it also operates as a function word in relation to the following verb pay to make the structure have $+\mathrm{N}+$ inf.

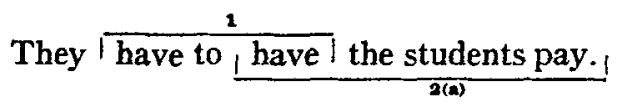

In the second example "They have had to have the students pay their own fares" the first have is the function word of formula No. 3 (signaling completed action); the second have, in the form had, operates both as the past participle of any verb would in formula No. 3 and also as have, the function word, in formula No. 1; the third have operates both as the infinitive (simple form) of any verb would in formula No. 1, and also as the function word have in formula No. 2, with the $\mathrm{N}$ (students) plus the infinitive or simple form of the full verb pay.

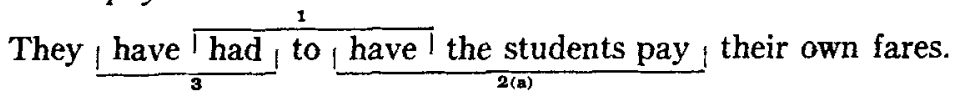

In similar fashion, in the third and fourth sentences, each have has a double structural use.

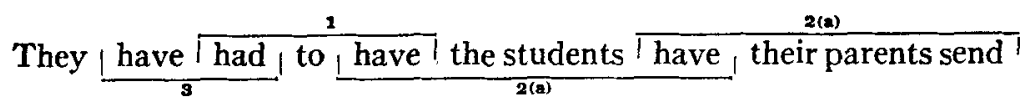
the money for their fares.

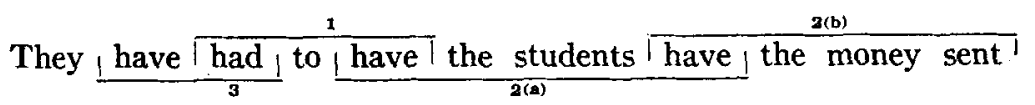
by their parents. 